\title{
Predominant Mutations Induced by the Thermococcus litoralis, Vent DNA Polymerase during DNA Amplification In Vitro
}

\author{
Phouthone Keohavong, ${ }^{1}$ Lucy Ling, Cremilda Dias, and William G. Thilly
}

\begin{abstract}
Center for Environmental Health Sciences, Massachusetts Institute of Technology, Cambridge, Massachusetts 02139;
${ }^{1}$ Department of Environmental and Occupational Health, Graduate School of Public Health, University of Pittsburgh, Pittsburgh, Pennsylvania 15238
\end{abstract}

\begin{abstract}
We have analyzed the predominant mutations created during DNA amplification by PCR utilizing a DNA polymerase isolated from the Thermococcus litoralis (Vent DNA polymerase). Exon 3 of the human hypoxanthine guanine phosphoribosyl transferase (HPRT) gene was amplified using conditions optimized for efficiency of DNA amplification. The resulting PCR product was subjected to denaturing gradient gel electrophoresis (DCCE) to separate polymerase-induced mutant sequences from correctly amplified sequences. The nature of induced mutations was determined by isolating and sequencing the mutant sequences from the gel. Eighteen predominant mutations were found in the 104-bp low temperature melting domain of exon 3 and consisted of $16 \mathrm{~A} / \mathrm{T}$ to $\mathrm{G} / \mathrm{C}$ transitions, a G/C to T/A transversion and a complex 4-bp deletion. Thus, the Vent exonuclease proofreading activity seems to affect all misincorporation events with apparently equal probability (i.e., by a factor of five). The comparison of the error rates between analogues of Vent DNA polymerase proficient and deficient in the proofreading $3^{\prime} \rightarrow 5^{\prime}$ exonuclease activity indicates that the lack of proofreading resulting in an approximate five-fold increase in induced error rate. However, the similarity of the patterns of the mutant sequences observed in DGGE suggested that both enzymes created predominantly the same kinds of mutations and at the same positions in
\end{abstract}

this DNA template under the in vitro reaction conditions studied. This predominance of $A / T$ to $G / C$ transition is also a characteristic of the Taq DNA polymerase, although the positions of most errors induced by both enzymes are not identical.

$\mathbf{T}_{\mathrm{h}}$ he value of $P C R^{(1-3)}$ in the study of rare mutational events in cell population or tissue is limited by the infidelity of DNA polymerases. ${ }^{(4-7)}$ By separation of the PCR products by denaturing gradient gel electrophoresis (DGGE), ${ }^{(8)}$ we have been able to characterize the fidelity of several DNA polymerases and associated reaction conditions during the amplification of the exon 3 of the human hypoxanthine phosphoribosyl transferase (HPRT) gene. ${ }^{(9)}$ This approach has the value of presenting varied local DNA contexts yielding an estimate of fidelity averaged over the entire sequence investigated. Furthermore, DGGE allows isolation of individual "hotspot" mutants so that the specific kinds of errors and their local sequence contexts can be determined. This information allows users of particular DNA polymerases in PCR to consider the probability that an isolated mutant sequence could have arisen from the PCR process, rather than having been present in the sample studied. Such knowledge may also contribute to the understanding of the basic mechanisms of the DNA polymerization process. In previous work, we reported the predominant errors for bacteriophage T4, modified T7, Klenow fragment, and Taq DNA polymerases. Recently, we have shown that the DNA polymerase of Thermococcus litoralis, Vent, had the useful advantages of both thermostability and increased fidelity relative to the more widely used Taq DNA polymerase derived from Thermus acquaticus. ${ }^{(2)}$

In this paper we report and discuss the results of our comparative study of the fidelity and the kinds of predominant mutations between Vent DNA polymerase and a Vent deficient in the proofreading $3^{\prime} \rightarrow 5^{\prime}$ exonuclease activity. (10)

\section{MATERIALS AND METHODS Materials}

Vent DNA polymerase isolated from Thermococcus litoralis, designated Vent (wt) in this study, and Vent deficient in $3^{\prime} \rightarrow 5^{\prime}$ exonuclease activity, designated Vent $\left(\mathrm{exo}^{-}\right)$, was from New England Biolabs. Taq DNA polymerase was purchased from Perkin Elmer-Cetus (Norwalk, Connecticut).

The 2'-deoxynucleoside-5'-triphosphates were purchased as $100-\mu \mathrm{M}$ solutions from Pharmacia (Piscataway, NJ). The oligonucleotides (Synthetic Genetic, CA) used as primers for PCR were P1, 5'CATATATTAAATATACTCAC-3'; P2, 5'TCCTGATTTTATTTCTGTAG-3'; P3, 5'. GACTGACGTCTTGCTCGAG-3'.

\section{Procedures}

To obtain radioactive DNA, PCR was carried out with 5 '-end-labeled primers (150 Ci/mmole) using $\left[\gamma^{3}{ }^{32} \mathrm{P}\right]$ ATP $(7000$ $\mathrm{Ci} / \mathrm{mmole}), \mathrm{T} 4$ polynucleotide kinase, and the reagents in the 5 '-end DNA ter- 
minus labeling system (Bethesda Research Laboratories, Gaithersburg, MD).

The DNA template used in this study was a 224-bp fragment containing the wild-type 184-bp exon 3 of the human HPRT gene surrounded at both ends by a 20-bp fragment from flanking intron sequences. ${ }^{(9)}$ The target fragment was prepared by an initial PCR amplification from genomic DNA isolated from human lymphoblastoid cells, line TK $6^{(11)}$ using primers $\mathrm{P} 1$ and $\mathrm{P} 2$, and Vent (wt) DNA polymerase. The resulting 224-bp fragment was boiled and reannealed and migrated through a denaturing gradient gel to separate the polymerase-induced mutant sequences from the wild-type homoduplex. The wild-type homoduplex DNA was isolated from the gel, and the number of molecules was determined by polyacrylamide gel electrophoresis (PAGE) analysis against known amounts of markers and standard DNA. ${ }^{(12)}$ To analyze the fidelity of DNA amplification, this wild-type 224-bp fragment was used as a template for further amplification using 5 '-end-labeled primers P1 + P3. The resulting 204 bp was gel purified from the reaction mixture and analyzed by DGGE under mutant/wildtype heteroduplex conditions. ${ }^{(9)}$

The conditions for DNA amplification were optimized for fidelity as described. ${ }^{(12)}$ In this study both the mixture and reaction conditions were identical for Vent ( $w t)$, Vent (exo $o^{-}$), and Taq DNA polymerases. Each $100-\mu$ l reaction mixture contained $20 \mathrm{mM}$ Tris ( $\mathrm{pH} \mathrm{8.5)}$ ) at $25^{\circ} \mathrm{C}, 10 \mathrm{~mm} \mathrm{KCl}, 10 \mathrm{~mm}\left(\mathrm{NH}_{4}\right)_{2} \mathrm{SO}_{4}$, $0.1 \%$ Triton X-100, $7.5 \mathrm{~mm} \mathrm{MgSO}_{4}, 0.5$ mm each dNTP, $10 \mu \mathrm{g}$ of BSA, $1 \mu \mathrm{M}$ each primer, and 4 units of each DNA polymerase. Each cycle of the PCR reactions consisted of $1 \mathrm{~min}$ at $94^{\circ} \mathrm{C}$ for DNA template denaturation, $2 \mathrm{~min}$ at $53^{\circ} \mathrm{C}$ for template-primer hybridization, and 2 min at $72^{\circ} \mathrm{C}$ for DNA polymerization. To analyze the PCR product by DGGE at 10$10^{4}$ - and $10^{7}$-fold amplification, each DNA polymerase was allowed to carry out the amplification from $10^{11}, 10^{8}$, and $10^{5}$ copies of the 244-bp fragment, respectively, to produce a total $10^{12}$ copies of the 204-bp fragment. To achieve a $10-, 10^{4}-$, and $10^{7}$-fold amplification, Vent (wt) and Taq, which had both an efficiency of amplification of $77 \%$, required 4, 16, and 28 PCR cycles, respectively, whereas Vent ( $\left.\mathrm{exo}^{-}\right)$with an efficiency of $85 \%$, required 4,15 , and 26 PCR cycles, respectively.

\section{DGGE Analysis and DNA Sequence Determination}

The conditions for DGGE analysis, for isolation and characterization of individual mutant sequences have already been described. ${ }^{(9,13)}$ In summary, the 204-bp radioactive DNA was PAGE-purified from each reaction mixture, and the total amount of radioactivity incorporated was determined by scintillation counting. DNA from each sample was boiled and reannealed so that each strand of the mutant homoduplexes hybridized with the complementary strand from the correctly amplified DNA or wild type present in excess. The DNA was then separated through a denaturing gradient gel in which the excess of wild-type homoduplex focused as a single band while the less stable mutant/wild-type heteroduplexes focused between the wild-type homoduplex and the top of the gel as patterns of discrete bands (see Fig. 1, below).

To determine the kind of each mutation, each visible mutant/wild-type heteroduplex band was isolated from the gel. The DNA was eluted from each gel portion, further amplified, and directly analyzed by a second DGGE. If a band isolated from the first denaturing gradient gel originally contained only one mutant/wild-type heteroduplex, then two major bands would be observed in the second denaturing gradient gel corresponding to one mutant and one wildtype homoduplex. If a band originally contained two or more mutant/wildtype heteroduplexes, then two or more mutant homoduplex bands would be detected in addition to the wild-type homoduplex band. The mutant homoduplexes were isolated from the gels and sequenced to determine the kinds and position of the mutations. ${ }^{(9,13)}$

The conditions for DNA sequencing were improved from those described by Keohavong and Thilly ${ }^{(9)}$ by omitting $\mathrm{NaC} 1$ from both the $16-\mu \mathrm{l}$ reaction mixture and from each of the four termination mixtures.

\section{RESULTS}

Comparison of the Patterns of Mutant/Wild-type Heteroduplexes among Vent (wt), Vent (exo-), and Toq DNA Polymerases

DNA amplifications were carried out under identical reaction mixture and reac- tion conditions for the three DNA polymerases. After 10-, $10^{4}$-, and $10^{7}$-fold amplification by each enzyme, the resulting 204-bp DNA was purified from each reaction mixture, and an equal amount of radioactivity from each sample was boiled and reannealed, and analyzed by DGGE. As shown in Figure 1, each amplified DNA revealed a specific pattern of mutant/wild-type heteroduplexes separated in lower denaturant concentrations of the gel from the excess of wild-type homoduplex. These data showed that for Vent (exo-) and Taq DNA polymerases, the patterns of mutant sequences constantly remain identical after an exponential 10-, $10^{4}-$, and $10^{7}$-fold amplification. For Vent (wt), however, an intense triplet appeared after a $10^{7}$-fold amplification in one of the three experiments performed, indicative of allelic preference in the amplification of this sequence. ${ }^{(9)}$

The amount of radioactivity in the heteroduplex region (between the wild type and the top of the gel) and that of wild-type homoduplex were recorded using a PhosphorImager. The background noise, due to nonspecific DNA binding in the gel, or depurination occurring during DNA handling, was measured from the control lanes loaded with only DGGE-purified wild-type DNA homoduplex sequences that had been subjected to the identical treatment of boiling, reannealing, and ethanol precipitation and run in the same gels as the experimental samples. The heteroduplex fraction (HeF), due to polymerase amplification, was calculated as: $\mathrm{HeF}=$ (Total heteroduplex counts - background heteroduplex counts)/total counts. The error rates $(f)$ can then be calculated using the following equation: $f=\mathrm{HeF} / b \times d$; where $b$ represents the 104 bases of the low temperature melting domain of exon 3 , and $d$ is the number of DNA doublings ( $d$ is 23 doublings for $10^{7}$-fold amplification).

The estimated mean error rate $f$, error per base doubling, was $5.3 \times 10^{-5}$ for Vent, $2.7 \times 10^{-4}$ for Vent (exo-) and $1.3 \times 10^{-4}$ for Taq DNA polymerases for $10^{7}$-fold amplification. The error rate at 23 doublings of amplification of $5.3 \times 10^{-5}$ for Vent ( $\left.w t\right)$ is comparable to the previously reported $5.5 \times 10^{-5}$ by Ling et al., ${ }^{(12)}$ and $2.2 \times 10^{-5}$ by Cariello et al., ${ }^{(14)}$ using the same approach and the same DNA template, and $3.0 \times 10^{-5}$ for this enzyme using the single round 


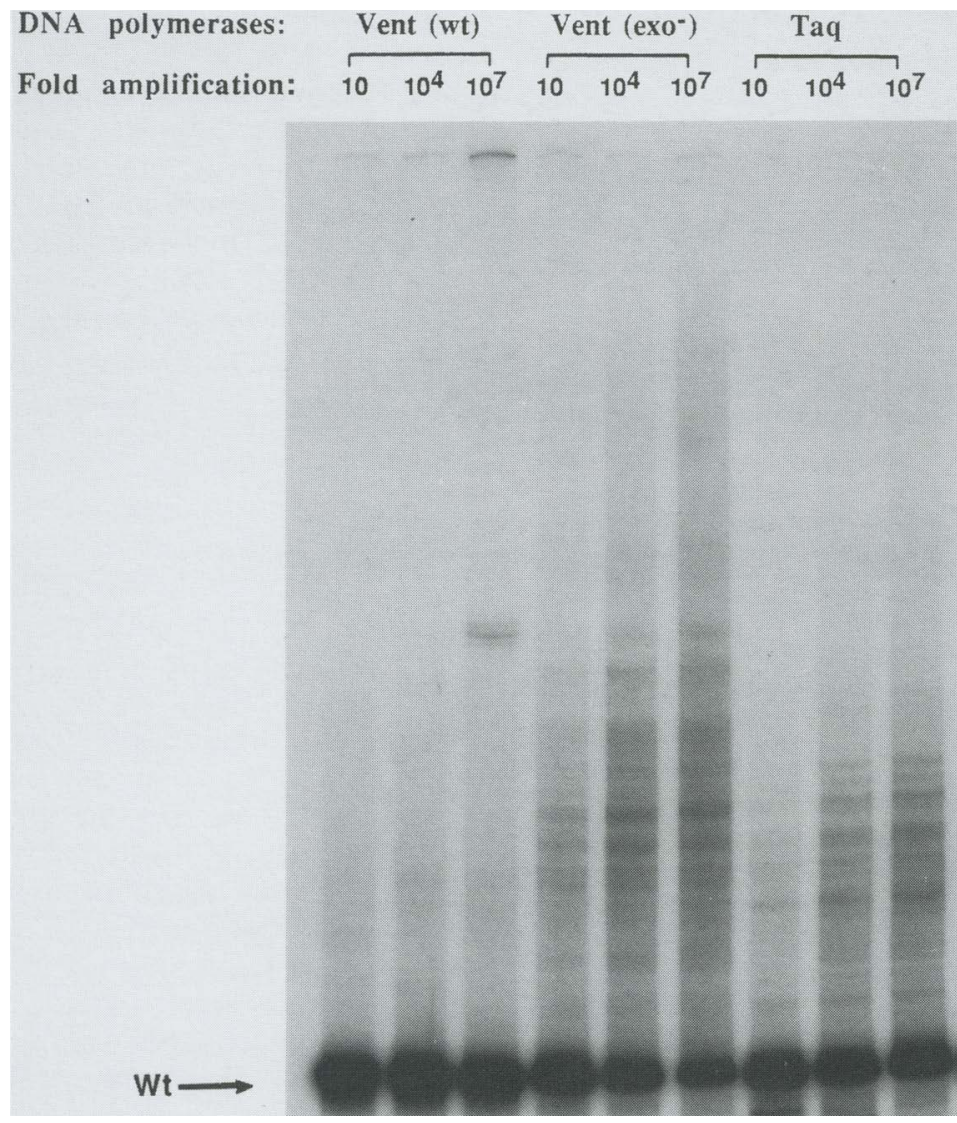

FIGURE 1 Analysis by DGGE of the PCR products after 10-, 104-, and $10^{7}$-fold amplification using the DNA polymerases indicated. To compare the fidelity of DNA amplification, the DGGEpurified 224-bp fragment containing wild-type exon 3 of the human HPRT gene (see Materials and Methods) was used as template for PCR. Copies of this fragment $\left(10^{11}, 10^{8}\right.$, and $\left.10^{5}\right)$ were amplified an additional 10-, $10^{4}-$, and $10^{7}$-fold (indicated at the top of each lane), respectively, using the same reaction mixture containing ${ }^{32} \mathrm{P}-5$ '-end-labeled primers $\mathrm{P} 1+\mathrm{P} 3$, the same reaction conditions, the DNA polymerases indicated, and the numbers of PCR cycles indicated in Materials and Methods. The amount of desired increase in DNA amplification was controlled by polyacrylamide gel analyzing an aliquot of each reaction mixture against known amount of DNA markers and by counting the amount of radioactivity incorporated in each sample. The resulting radioactive 204-bp fragment was gel-purified from each mixture and $5 \times 10^{4} \mathrm{cpm}$ aliquots were boiled and reannealed, and separated as heteroduplexes on a $12.5 \%$ polyacrylamide gel containing $16 \%$ to $30 \%$ denaturant gradient (top to bottom). (Wt) The position of the wild-type homoduplex.

of DNA synthesis and the phage M13mp2. ${ }^{(10)}$ The difference may be attributed to the slight variations in the composition of the reaction mixtures used in each study. $(10,12,14)$

\section{Analysis of Predominant Mutations}

For each enzyme, the patterns of mutant/wild-type heteroduplexes observed remained identical during the course of amplification from $10-, 10^{4}$-, and $10^{7}$ fold, with one exception for Vent (wt), which revealed an intense mutant band after a $10^{7}$-fold amplification (see Fig. 1). Comparison among the three DNA poly- merases in Figure 1 showed that Vent $(w t)$ and Vent $\left(e x 0^{-}\right)$created identical patterns of mutant sequences indicating that they induced predominantly the same kinds of mutations at the same positions within the template used. Several of the mutant bands produced by Taq DNA polymerase appeared to focus at the same positions as those seen with Vent (wt) or Vent (exo-). This suggested that the three enzymes created some common mutations with regard to the kinds and positions in the template studied and under the reaction conditions used.

Hotspot mutations have determined previously for Taq within this same target sequence. ${ }^{(9)}$ In this study we determined the kinds and positions of hotspot mutations induced by Vent (wt) DNA polymerase. All discrete bands created by Vent (wt) (see Fig. 1) were excised from the gel, the DNA was eluted from each gel slice, further amplified, and subsequently characterized by a second DGGE as described in Materials and Methods. After characterization, a total of 18 different hotspot mutant sequences were identified by DGGE for Vent DNA polymerase. Figure 2 shows for each of the 18 mutant alleles (mutants $a-r$ ) the positions of the mutant homoduplex (indicated by an arrow) and those of the two respective mutant/ wild-type heteroduplexes relative to the position of the wild-type homoduplex (wt). Sequencing analysis of the mutant homoduplexes revealed that they consisted of $16 \mathrm{~A} / \mathrm{T}$ to $\mathrm{G} / \mathrm{C}$ transitions, one $\mathrm{G} / \mathrm{C}$ to T/A transversion, and one complex 4-bp deletion in which the last 10 bp at the $3^{\prime}$ end of exon 3, 5'-GAGCTATTGT-3', was replaced by a 6-bp sequence, $5^{\prime}$-CGTCTT-3', resulting in a 4 -bp deletion (see Fig. 3).

\section{DISCUSSION}

The thermostable Vent DNA polymerase induced predominantly $A / T$ to $\mathrm{G} / \mathrm{C}$ transitions in the low temperature melting domain of exon 3 of the human HPRT gene and under the reaction conditions given in Materials and Methods. The same kinds of predominant mutations have also been found for Taq DNA polymerase within this same DNA sequence $^{(9)}$ and other templates. ${ }^{(2,15)}$ Furthermore, 5 of the $16 \mathrm{~A} / \mathrm{T}$ to $\mathrm{G} / \mathrm{C}$ transitions induced by Vent DNA polymerase (mutations $b, e, i, m$, and $p$ ) were identical to those found for Taq DNA polymerase in our previous study ${ }^{(9)}$ consistent with the observation in Figure 1 that the two enzymes appeared to share several common bands in their patterns of mutant/wild-type heteroduplexes. On the basis of exact correspondence between the patterns of hotspot mutant bands (Fig. 1) we conclude that predominantly the same mutations were induced by Vent $\left(\mathrm{exo}^{-}\right)$in this study. Hotspot mutant sequences induced by Vent $\left(\right.$ exo $\left.^{-}\right)$were not determined by sequencing. The origin or the mechanisms of mutagenesis by these DNA polymerases leading to the predominant formation of 


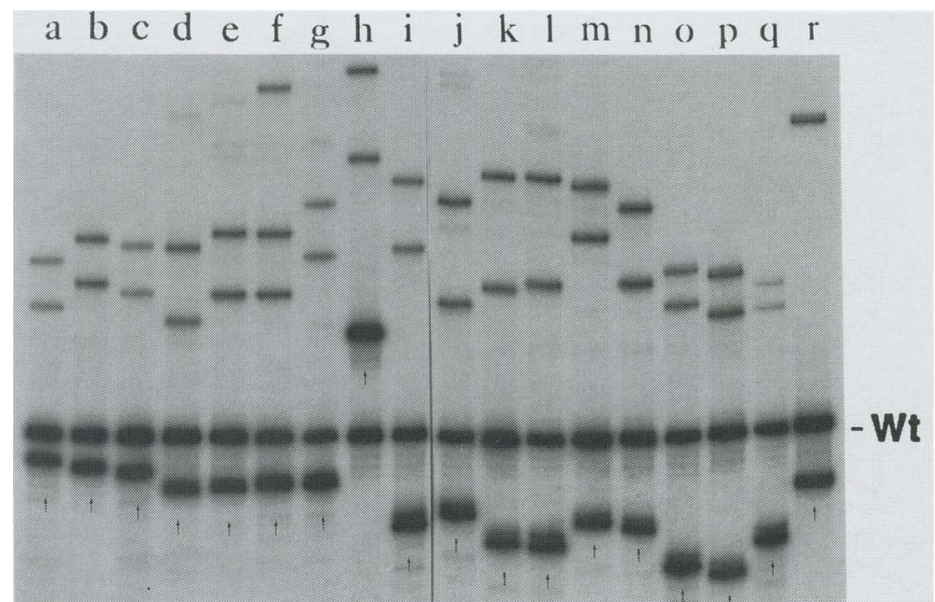

FIGURE 2 Analysis by DGGE of individual mutant sequences produced by Vent (wt) DNA polymerase. Discrete mutant/wild-type heteroduplex bands in lane $10^{7}$-fold amplification with Vent $(w t)$, as shown in Fig. 1, were isolated from the gel, further amplified, characterized by a second DGGE, and the kinds and positions of the mutations identified as described in Materials and Methods. From each of the 18 different mutant homoduplexes identified, $2 \times 10^{3} \mathrm{cpm}$ equivalent were boiled and reannealed with wild-type DNA to partially generate mutant/wild-type heteroduplexes and analyzed by the same type of DGGE as in Fig. 1. Shown are the position of the wild-type homoduplex ( $W t$ ), those of each mutant homoduplex (indicated by an arrow), and those of the two respective mutant/wild-type heteroduplexes distributed between the wild type and the top of the gel. For mutant $r$, the two respective mutant/wild-type heteroduplexes were unseparated and focused at the same position of the gel.

base-pair substitutions and especially the $A / T$ to $G / C$ transitions are unclear. It is unlikely to be the result of DNA damage during DNA denaturation at high temperature such as deamination of cytosine to produce uracil or the spontaneous base hydrolysis leading to apurinic or apyrimidic sites, as these types of damage would have led to a $C / G$ to $T / A$ transitions. $^{(15,16)}$ Rather, this kind of mutation may have resulted from the extension of base-mispairing T-G (or A-C) leading to the formation of $A / T$ to $G / C$ transitions. ${ }^{(15,17)} \quad$ Furthermore, our present results show (Fig. 3) that 12 of the $16 \mathrm{~A} / \mathrm{T}$ to $\mathrm{G} / \mathrm{C}$ transitions occurred at the level of an adenine flanked $3^{\prime}$ or $5^{\prime}$ by a guanine. Either - AG - or - GAwas converted to $-\mathrm{GG}$ - in mutant alleles. This may indicate an important role of neighboring base or template sequence in the induction of hotspot mutation by Vent (wt) DNA polymerase.

The 4-bp deletion (mutation $r$, Fig. 3) corresponded to the replacement of the 10-bp sequence 5'-GAGCTATTGT-3' (positions 394-403) immediately adjacent to the 3' end of primer P1 by a new 6-bp sequence $5^{\prime}$-CGTCTT-3'. This mutation had also been found to be produced by Klenow fragment of the DNA Po1I after a $10^{8}$-fold amplification in our previous study. ${ }^{(9)}$ In both cases, this mutation appeared to have resulted from an amplifi-

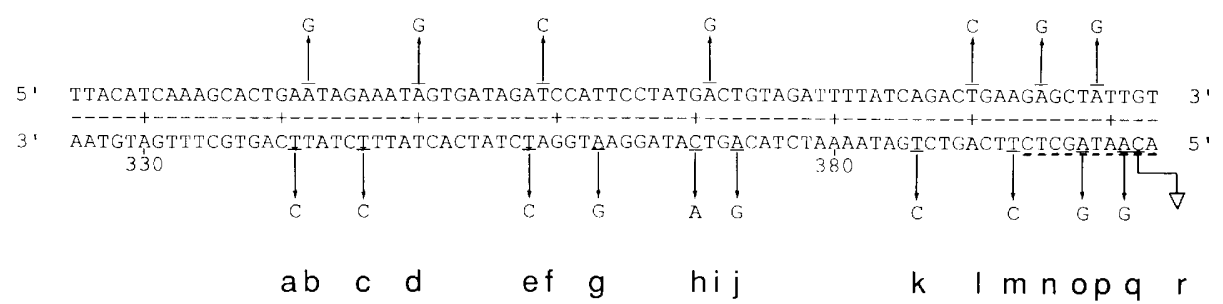

FICURE 3 Summary of the kinds and positions of the mutations induced by Vent (wt) DNA polymerase in the low temperature melting domain of exon 3 . The 18 predominant mutations found (designated $a-r$ ) were located between base-pair position 325 and $3^{\prime}$ end of exon 3 at position 403 . The last 10 -bp sequence at the 3 ' end of exon 3 involving the complex 4 -bp deletion that resulted in mutation $r$ is underscored by a broken line. cation with an efficiency significantly higher than that of the wild type or those of other mutant alleles [See Fig. 1, lane labeled $10^{7}$-fold amplification for Vent $(w t)]$. We have named this phenomenon "allelic preference" in DNA amplification. ${ }^{(9)}$ In both cases, however, this phenomenon occurred in only one out of the three independent experiments performed and at a high number of amplification cycles. The occurrence in one of the three trials suggests that the mutation itself arises at very low frequency.

Our comparative study of Vent (wt) and Vent $\left(e^{-} o^{-}\right)$shows that the deficiency of the proofreading $3^{\prime} \rightarrow 5^{\prime}$ exonuclease activity in Vent $\left(\mathrm{exo}^{-}\right)$polymerase resulted in a five-fold decrease in fidelity. This is in agreement with the error rate reported for this enzyme using a single round DNA synthesis using the phage M13mp2. ${ }^{(10)}$ Furthermore, the identity of the mutational spectra produced by both enzymes (see Fig. 1) appears to indicate that the $3^{\prime} \rightarrow 5^{\prime}$ exonuclease activity in Vent proofreads all misincorporation events with the same efficiency. These observations may be of importance in considering the molecular mechanisms of proofreading. However, it is important to point out here that all such observations may critically depend on the reaction conditions and the DNA template used.

\section{ACKNOWLEDGMENTS}

This work was supported by grants from the U.S. National Institute of Environmental Health Sciences (P42-ES04675, PO1-ES00597, P50-ES03926-05) and the Office of Health and Environmental Research, U.S. Department of Energy (DEFG02-86-ER60448).

\section{REFERENCES}

1. Mullis, K.B. and F.A. Faloona. 1987. Specific synthesis of DNA in vitro via a polymerase-catalyzed chain reaction Methods Enzymol. 155: 335-350.

2. Saiki, R.K., D.H. Gelfand, S. Stoffel, S.J. Scharf, R. Higuchi, G.T. Horn, K.B. Mullis, and H.A. Erlich. 1988. Primer-directed enzymatic amplification of DNA with a thermostable DNA polymerase. Science 239: 487-491.

3. Kleppe, K., E. Ohtsuka, R. Kleppe, I. Molineux, and H.G. Khorona. 1971. Studies on polynucleotides. XCVI. Repair replications of short synthetic DNAs as cata- 
lyzed by DNA polymerase. J. Mol. Biol. 56: 341-361.

4. Muzyczka, N., R.L. Poland, and M.J. Bessman. 1972. Studies on the biochemical basis of spontaneous mutations. A comparison of the deoxyribonucleic acid polymerases of mutator, antimutator, and wild type strains of bacteriophage T4 $J$. Biol. Chem. 247: 7115-7142.

5. Goodman, M.F., W.C. Gore, N. Muzyczka, and M.J. Bessman. 1974. Studies on the biochemical basis of spontaneous mutation. Rate model for DNA polymerase-effected nucleotide misincorporation. $J$. Mol. Biol. 88: 423-435.

6. Loeb, L.A. and T.A. Kunkel. 1982. Fidelity of DNA synthesis. Annu. Rev. Biochem. 52: 429-457.

7. Kunkel, T.A., L.A. Loeb, and M.F. Goodman. 1984. On the fidelity of DNA replication. J. Biol. Chem. 259: 1539-1545.

8. Fischer, S.G. and L.S. Lerman. 1983. DNA fragments differing by single base-pair substitutions separated in denaturing gradient gel: correspondence with melting theory. Proc. Natl. Acad. Sci. 80: 15791583.

9. Keohavong, P. and W.G. Thilly. 1989. Fidelity of DNA polymerases in DNA amplification. Proc. Natl. Acad. Sci. 86: 92539257.

10. Mattila, P., J. Ronka, T. Tenkanen, and K. Pitkanen. 1991. Fidelity of DNA synthesis by the thermococcus litoralis DNA polymerase, an extremely heat stable enzyme with proofreading activity. Nucleic Acids Res. 19: 4967-4976.

11. Skopek, T.R., H.L. Liber, P.W. Penman, and W.G. Thilly. 1978. Isolation of human lymphoblastoid line heterozygous at the thymidine kinase locus: Possibility for a rapid human cell mutation assay. Biochem. Biophys. Res. Commun. 84: 411-416.

12. Ling, L., P. Keohavong, C. Dias, and W.G. Thilly. 1991. Optimization of the polymerase chain reaction with regard to fidelity: Modified T7, Taq, and Vent DNA polymerase. PCR Methods Applic. 1: 67-93.

13. Keohavong, P., V.F. Liu, and W.G. Thilly. 1991. Analysis of point mutations induced by ultraviolet light in human cells. Mut. Res. 249: 147-159.

14. Cariello, N.F., T.A. Swenberg, and T.R. Skopek. 1991. Fidelity of the Thermococcus litoralis DNA polymerase (Vent) in polymerase chain reaction determined by denaturing gradient gel electrophoresis. Nucleic Acids Res. 19: 4193-4198.

15. Eckert, K.A. and T.A. Kunkel. 1991a. The fidelity of DNA polymerases used in the PCR. In Polymerase chain reaction I: A practical approach (ed. M.J. McPherson, P. Quirke, and G.R. Taylor). IRL Press, Oxford University Press, Oxford.

16. Eckert, K.A. and T.A. Kunkel. 1991b. DNA polymerase fidelity and the polymerase chain reaction. PCR Methods Applic. 1: 1724.

17. Loeb, L.A. and B.P. Preston. 1986. Mutagenesis by apurinic/apyrimidic sites. Annu. Rev. Genet. 20: 201-230.

Received November 19, 1992; accepted in revised form on January 11, 1993. 


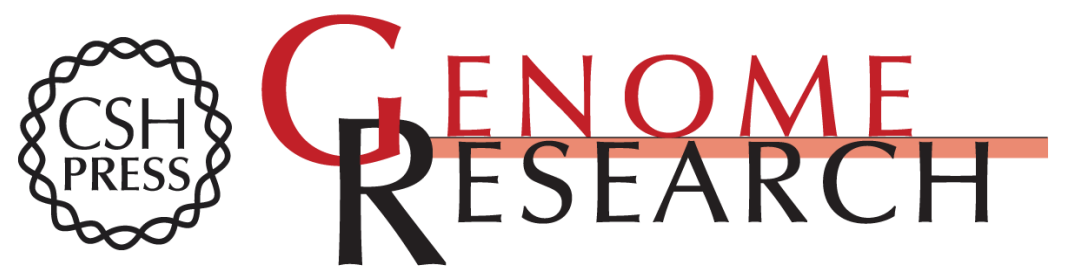

\section{Predominant mutations induced by the Thermococcus litoralis, vent DNA polymerase during DNA amplification in vitro.}

P Keohavong, L Ling, C Dias, et al.

Genome Res. 1993 2: 288-292

Access the most recent version at doi:10.1101/gr.2.4.288

References This article cites 16 articles, 4 of which can be accessed free at:

http://genome.cshlp.org/content/2/4/288.full.html\#ref-list-1

\section{License}

Email Alerting Receive free email alerts when new articles cite this article - sign up in the box at the Service top right corner of the article or click here.

\section{Affordable, Accurate Sequencing.}

To subscribe to Genome Research go to:

https://genome.cshlp.org/subscriptions 